\title{
Los efectos de 1968 sobre la historiografía occidental
}

\author{
Carlos Antonio Aguirre Rojas ${ }^{1}$
}

\section{Repensando la significación y caracterización de la revolución cultural de 1968}

Cincuenta años después de ese gran "acontecimiento-ruptura" que ha sido el simbólico año de 1968, resulta mucho más fácil tratar de medir y de comprender adecuadamente su verdadera y profunda significación. Porque con la distancia de estas cinco décadas transcurridas, es ahora más claro que 1968 es solamente el punto de concentración, y el reflejo más evidente y espectacular, de un momento más amplio de profundos cambios revolucionarios, que recorren prácticamente todo el planeta y que abarcan lo mismo a la gran Revolución Cultural china desatada en 1966 que al otoño caliente italiano de 1969, pasando obviamente por el célebre mayo francés, la primavera de Praga checoslovaca, la trágica masacre de los estudiantes y de la población mexicana en octubre de 1968, el breve ensayo de insurrección del "Cordobazo" argentino o los distintos movimientos de ocupación de instalaciones en Nueva York o Berkeley en los Estados Unidos, entre tantos y tantos otros. ${ }^{2}$

Porque hoy resulta claro que el parteaguas fundamental de 1968 se ha desplegado en escala mundial. Y, también, es claro ahora que, más allá de sus múltiples y muy diversas formas de manifestación en los distintos puntos del globo, asociadas obviamente a las particularidades históricas de cada región, nación o espacio respectivo, el movimiento de 1968 es en el fondo una verdadera revolución cultural. Y así, lo mismo es sus epicentros más representativos y característicos que en todo el conjunto de los lugares y espacios de su múltiple irrupción, la fractura histórica de 1968 se manifiesta, siempre doblemente, como un proceso cuya explicación nunca logra agotarse

1 Mexicano, Doctor en Economía. Instituto de Investigaciones Sociales, Universidad Nacional Autónoma de México, México. E-mail: aguirrec@unam.mx

Este texto es una versión traducida y actualizada del trabajo publicado bajo el nombre "1968 as a turning point in historical thinking: changes in western historiography" (2004), publicado en História (São Paulo), Vol. 23, № 1-2. Sao Paulo: Universidade Estadual Paulista, pp. 197-218.

2 Sobre la caracterización general de este movimiento cfr. Wallerstein (1989) y también Arrighi, Hopkins y Wallerstein (1992). 
del todo si nos atenemos exclusivamente a los datos de la situación local o nacional correspondiente -remitiéndonos entonces siempre, también, a su dimensión universal o planetaria-, y también como una transformación que, sea cual sea la suerte política o el destino inmediato y mediato de sus protagonistas directos, tanto individuales como colectivos, termina siempre por trastocar radicalmente y sin vuelta atrás posible a los modos de funcionamiento y de reproducción de las estructuras culturales principales a las que impugna y cuestiona. ${ }^{3}$

Readaptándose entonces a las condiciones del mundo capitalista desarrollado, como en el movimiento del mayo francés, o a las encrucijadas principales de los distintos proyectos de las sociedades del socialismo real, como en el caso de la revolución cultural china y luego de la trágica primavera de Praga, o finalmente, a las peculiaridades de los contextos de los países del tercer mundo y subdesarrollados, como la experiencia del movimiento estudiantil-popular mexicano, la revolución de 1968 "recorre verdaderamente el mundo", para anticipar la crisis económica mundial desatada en 1972-1973, para generar el nacimiento o el relanzamiento de los nuevos movimientos sociales desplegados en los últimos cincuenta años, para construir las condiciones de emergencia de las "nuevas izquierdas" revolucionarias y para hacer posible, finalmente, la renovación total y completa de la esfera cultural de las sociedades modernas del mundo entero.

Ya que si nos preguntamos acerca de los trazos comunes que comparten todos esos movimientos y revueltas que, en todo el planeta, han protagonizado y representado el espíritu de la protesta y de la oposición al sistema durante los años de 1966 a 1969, será fácil reconocer que en todos ellos, y más allá de la diversidad de sus circunstancias concretas, lo que se pone en cuestión y se intenta cambiar es sobre todo la lógica del funcionamiento y el modo mismo de expresión de las formas dominantes de la cultura entonces vigente. Con lo cual parece haber una especie de trama única y secreta que vincula y conecta a través de sus múltiples hilos, a la impugnación radical de la cultura antidemocrática, autoritaria, jerárquica y sorda a los reclamos de la sociedad civil de todos los países del llamado "tercer mundo", y a la crítica también demoledora y total de la cultura consumista, alienante, estandarizada, superficial y también extremadamente rígida del mundo capitalista desarrollado, con la crítica vigorosa y enérgica de la "falsa cultura socialista" o de la cultura oficial anquilosada del entonces llamado mundo socialista. Una triple vertiente de esta revolución cultural de 1968 que, si bien se ha focalizado en los epicentros evidentes de la ciudad de México, de París, de

3 Al respecto cfr. Wallerstein (1989), Braudel (1993 y 1997), y Aguirre (1993, 2008 y 2010b). 
Pekín y de Praga, se ha manifestado igualmente a lo largo y ancho de los distintos países y de los distintos continentes de todo el globo. ${ }^{4}$

Y en todos ellos, poniendo en el centro de su impugnación a ese plano ya mencionado de la cultura contemporánea. Pues si 1968 no es un simple cambio menor o una simple mutación, sino una verdadera revolución, y si dicha revolución es sobre todo de orden cultural, entonces es lógico que lo que ha cambiado después de 1968 es sobre todo la naturaleza y la función esencial de las tres instituciones principales dentro de las cuales se produce, genera, mantiene y reproduce dicha cultura moderna, es decir, las instituciones de la familia, de la escuela y de los medios masivos de comunicación. $Y$ es justamente aquí, en el seno de estos tres aparatos de la reproducción cultural contemporánea, en donde la marca del paso de la revolución de 1968 se ha impreso de manera definitiva, marcando en la historia de estos tres espacios un claro antes y un después.

Pues viendo una vez más el problema desde una perspectiva mundial y de largo aliento temporal, es claro que la familia que existió en todo el mundo hasta los años cincuenta del siglo veinte tiene poco que ver con la familia que hoy conocemos. Y no solo porque con la revolución creada por la invención de la píldora anticonceptiva se descubrió un método de control y de planificación del tamaño de la familia y del momento deseado de su construcción, sino también por el hecho de que entre la familia de hace cincuenta y cinco años y la actual están de por medio todas las conquistas y los avances del moderno movimiento feminista, y también todos los efectos, a veces más sutiles e indirectos pero no menos efectivos, de la difusión del psicoanálisis y de la antipsiquiatría contemporáneas.

Progresos radicales de la célula familiar, desencadenados por el auge de esos movimientos sociales post-68 que son el feminismo y la antipsiquiatría, que se han expresado lo mismo en las exploraciones de la generación de los años setenta de nuevas formas de organización de la familia -desde las célebres "comunas" de los movimientos hippies, hasta los experimentos feministas de la maternidad exclusiva sin padres varones-, que en el aumento espectacular de la tasa de divorcios en todo el mundo, igual que en la ahora cotidiana evocación de la "crisis de la pareja", pero también en el desarrollo generalizado de los "derechos y deberes de los niños", en el cambio total

4 Sobre esta difusión y para el caso solo de Francia véase el mapa reproducido en el núm. 264 de los Dossiers et Documents de Le Monde (IV-1998: 5). También el capítulo primero del libro de Faure (1998). Aunque los mejores trabajos sobre los movimientos del 68 comienzan haciendo casi siempre el repaso de los principales puntos del estallido del movimiento en el mundo, muy pocos se preguntan seriamente y abordan el tema complejo de las causas profundas de esa simultaneidad planetaria. Y es esa la idea que aquí intentamos subrayar, y que ha sido especialmente abordada por Immanuel Wallerstein en sus ensayos ya citados. 
del rol social y familiar de las mujeres, y hasta en la distinta percepción y papel de las generaciones más viejas dentro de ese mismo espacio familiar. ${ }^{5}$

Al mismo tiempo, y secundando a esta revolución total del modo de funcionamiento del núcleo familiar, también van a mutar completamente las estructuras internas del aparato escolar. Pues los estudiantes que escribían sobre los muros de París la consigna: "Profesores, ustedes son viejos... y su cultura también" lo que impugnaban centralmente era un claro esquema de transmisión del saber, esquema de relaciones jerárquicas y completamente verticales en donde el maestro se asume como el único depositario del saber, recreando la supuesta verdad de la sentencia Magister dixit, mientras que los estudiantes son considerados solo receptores pasivos, que escuchan, reciben y aprenden, sin reaccionar o interactuar de manera más activa con dichos maestros. Una escuela que funciona entonces reproduciendo un esquema disciplinario mucho más extendido dentro de todo el cuerpo social, y desde las lógicas más tradicionales de ejercicio del saber-poder, cuyo modelo no sobrevivirá indemne al choque brutal de 1968. ${ }^{6}$ Porque no es casual que luego de 1968 florezcan en todo el mundo los grandes debates pedagógicos, que intentan crear nuevos modelos de transmisión del saber, que sean capaces justamente de incorporar, de manera activa, participativa, crítica y creativa a los alumnos, haciendo más horizontal su relación con los profesores y renovando las formas tanto de generación como de transmisión de los nuevos conocimientos.

Una revolución de la institución escolar que es simultáneamente un cambio de la "escuela capitalista" y que en los países "socialistas" va a expresarse tanto a través de la impugnación específica de la vieja división entre trabajo manual y trabajo intelectual y también como crítica y rediscusión del rol social y de la función particular del estrato de los "intelectuales" dentro de la sociedad, como en el doble movimiento de acercar el taller a la escuela y la escuela a la fábrica y al campo.

5 Sobre este punto, cfr. Hobsbawm (1996). Sin embargo, aunque Hobsbawm refiere varios de estos cambios, su evaluación del movimiento de 1968 es completamente distinta de la que aquí desarrollamos. En cualquier caso, en nuestra opinión, la "revolución cultural" que él intenta explicar como un proceso más lento y gradual, correspondiente a todo el período 1945-1990, proceso que sería paralelo a la "revolución social" de estos mismos años, desdibuja finalmente el sentido radical de la ruptura de 1968, la que en este análisis es reducida casi al rango de algo anecdótico o poco relevante. Para otra evaluación de este mismo periodo 1945-1990, que al contrario subraya especialmente el punto de quiebre de los años 1967-1973, cfr. Hopkins y Wallerstein (1996).

6 Quien mejor ha desmontado, críticamente, esta estructura disciplinaria de la escuela -presente igualmente en la fábrica, los hospitales, las prisiones, el ejército, etc.- es, sin duda, Foucault (1993). 
Modificaciones esenciales en la función y carácter de la escuela y de la familia que se acompañan finalmente, también de un cambio significativo en el papel que a partir de esta fecha van a jugar los medios de comunicación de masas dentro de la sociedad. Porque, después de 1968, es evidente que dichos medios de comunicación van a pasar de una situación de presencia más bien marginal y limitada a las clases altas y medias de la sociedad, a una condición en la cual van a convertirse en artículos de consumo ampliamente popular, comenzando a jugar el rol de verdaderos formadores de opinión pública, y desarrollando nuevas funciones informativas, educativas y generativas de una cultura que eran completamente inexistentes antes del fin de esos años sesenta.

Multiplicando de manera significativa el tiraje de los periódicos y de las revistas de gran circulación, así como la audiencia y capacidad de difusión de la radio, la televisión y el cine, estos medios de comunicación empiezan a competir con la escuela y con la familia en el proceso de transmisión y circulación de todo tipo de información, pero también y más allá, en el proceso mismo de formación de las conciencias, de difusión de ciertos modelos de vida y de comportamiento, y de definición y establecimiento de complejos patrones culturales de reciente creación y elaboración. ${ }^{7}$

Incidiendo de esta manera en esos tres espacios privilegiados de gestación y de reproducción de la cultura que son las escuelas y universidades, los medios de comunicación masiva y la familia, la revolución de 1968 desestructuró al conjunto de las formas vigentes de esa misma cultura contemporánea, cerrando un capítulo importante de dicha historia cultural e inaugurando las formas de organización y de creación de la cultura que se han desarrollado durante los últimos cincuenta años y hasta la actualidad. ${ }^{8}$

Y a tono con estos cambios esenciales, se han modificado tanto la configuración de los saberes modernos y todo el conjunto de los distintos paisajes culturales del orbe, como también los procesos de conformación de nuevos sujetos, de nuevos movimientos sociales y de una nueva izquierda. Y todo ello, obviamente, ha terminado por impactar de una manera profunda a los propios perfiles generales de la historiografía contemporánea posterior a 1968, de un modo que vale la pena intentar reconstruir con más detenimiento y atención.

7 Con lo cual, solo van a desplegar hasta el final muchas de las funciones que ya habían sido agudamente analizadas, para los medios de comunicación de su época, por Walter Benjamin, en varios de sus ensayos incluidos en Essais / y Essais I/ (1983a y 1983b).

8 Solo para el caso francés, y a nivel puramente descriptivo, cfr. Le Goff (1998). También los artículos de Zancarini-Fournel (1998) y Dosse (1998). 


\section{La irrupción del presente en la historia}

Dado el enorme anhelo de cambio que se expresó en 1968, y dada la radicalidad de sus formas de manifestación a lo largo y ancho del mundo, no hay duda alguna de que este mismo movimiento significó, para todas las sociedades de aquellos tiempos, una definitiva irrupción del presente y de su vigencia total en el conjunto de las conciencias que lo protagonizaron y que lo presenciaron de cerca. Y dado que, en todos los casos, lo que los movimientos del 68 querían transformar era su propio presente, subvirtiendo la realidad alienada o falsificada o autoritaria en que vivían, entonces su despliegue desembocó, necesariamente, en el hecho de poner en el centro de la atención a la experiencia vivida inmediata, a los hechos candentes y esenciales de la más viva actualidad.

"Vivir sin tiempo muerto y gozar sin trabas" es otra de las consignas del 68, consigna que expresa de modo enfático esa reasunción y actualización radical del presente, que es propia de todo tiempo de revolución, y que de manera significativa va a impactar a los estudios históricos post-68. Pues, desde esta perspectiva, resulta claro que es a raíz de esta revolución cultural del segundo lustro de los años sesenta que el presente va a manifestarse con mucho más fuerza dentro de la historiografía, rompiendo con la rígida división entre presente y pasado que antes era aún dominante, e instalando de pleno derecho y en múltiples formas a la actualidad dentro de los objetos y temas pertinentes y habituales de estudio de la investigación historiográfica. Porque, en contra de una visión tradicional y reductora de la historia, que había sobrevivido hasta 1968, y que afirmaba que la historia era solo la ciencia "del pasado", el último medio siglo transcurrido va a presenciar en cambio la afirmación de una postura que, cada vez más difundida y aceptada, afirma que la historia es la ciencia "de los hombres en el tiempo" y, por lo tanto, ciencia del más absoluto y candente presente, lo mismo que de los muchos y muy diversos pasados ya acontecidos. ${ }^{9}$

Una visión que va a reivindicar también al presente como objeto de estudio de la historia, que no ha sido inventada después de 1968, sino que remonta sus filiaciones más antiguas a toda una tradición crítica y marginal que arranca desde Marx y que se prolonga hasta el día de hoy, pasando por autores como Marc Bloch, Walter Benjamin, Norbert Elias o Fernand Braudel, entre tantos otros. Tradición que ha sido y continua siendo minoritaria en todo el planeta, y que sin embargo va a ganar una batalla importante en torno a este punto, como fruto de los efectos de 1968: pues si ya Marx, los Annales y la Escuela de Frankfurt, etcétera, habían "reivindicado" al presente

9 Sobre este punto, cfr. Dosse (1989). 
como historia, 1968 va en cambio a legitimarlo de manera definitiva dentro de la actividad historiográfica, volviéndolo uno de los campos ineludibles de investigación de esa misma actividad.

Legitimación e incorporación irreversible del presente en la historiografía que va a manifestarse de múltiples formas, en los distintos espacios historiográficos nacionales. Por ejemplo, y en primer lugar, en el enorme auge que desde hace diez lustros va a tener la rama y el método de la historia oral, de esta historia apoyada en los testimonios directos de los hombres todavía vivos, que es por fuerza una historia del pasado más inmediato y del presente, y en consecuencia de hechos y procesos todavía frescos, recientes, cercanos y muchas veces todavía actuantes y vigentes. ${ }^{10}$

Una historia oral que, además, no se reduce simplemente a recabar y utilizar el testimonio directo de los testigos o protagonistas todavía vivos de una cierta realidad histórica cercana o inmediata, sino que también incluye, en sus versiones más radicales, a la intención explícita de "darle voz" a los propios agentes históricos, incorporándolos ahora también como creadores de la propia historia escrita de sus experiencias y acciones históricas diversas. Pues dado que, según estas posturas radicales, son las masas y las clases populares las que realmente hacen la historia, es entonces lógico y necesario que sean ellas también los que escriban su propia historia, participando activamente en la investigación historiográfica de sus propias experiencias y construyendo directamente, junto a los historiadores, las obras y los resultados principales del quehacer historiográfico. Historia radical del presente y del pasado inmediato, que incorpora y reivindica entonces a una historia oral que va mucho más allá de la simple entrevista o del clásico relato de vida, técnicas que, igualmente, se han popularizado y difundido en gran escala luego de la ruptura de 1968. ${ }^{11}$

Pero también, esta "presentificación" de la historia va a manifestarse dentro de los ambientes académicos de las ciencias sociales, provocando una importante "migración" de los especialistas del presente hacia la historia. Y así, después de 1968, será común que los sociólogos y los cientistas políticos, lo mismo que los economistas, comiencen a incursionar en la historia, aportando una vez más sus enfoques a la disciplina histórica y ocupándose sobre todo de esos mismos periodos del pasado reciente y del presente, que ahora son legitimados e incorporados por la historiografía de manera

10 Nos referimos a los trabajos clásicos y bien conocidos de Paul Thompson (1975) y de Philippe Joutard (1983). Y vale la pena subrayar que ya existe, desde hace varios lustros, una Asociación Internacional de Historia Oral, con su propia revista particular.

11 Cfr., por citar solo un caso, los trabajos del Grupo de la revista History Workshop, por ejemplo Samuel (1975 y 1984). 
más vasta y popular. Igualmente y en esta misma línea, es que se explica la multiplicación de nuevas instituciones académicas que ahora van a ocuparse de esa historia inmediata, instituciones como el Institut d'Histoire du Temps Present en Francia, que relanzarán de manera importante el rol de la historia más contemporánea dentro de los estudios históricos, y que se dedicarán de manera importante al rescate de archivos y a la recolección de testimonios y documentos de todos los protagonistas y personajes del propio siglo XX.

\section{Cambiando la agenda de los temas de la historia}

1968 es sobre todo una profunda y estructural revolución cultural. Entonces, al irrumpir con fuerza en el plano de la "cultura" contemporánea y de sus principales mecanismos de reproducción, el movimiento del 68 desestructuró a esta esfera de la totalidad social, movilizando todos los reflectores del drama histórico hacia dichas dimensiones culturales, y abriendo el espacio para el auge evidente que el estudio de la historia de todos estos temas va a tener durante los últimos cincuenta años transcurridos.

Con lo cual, no es una casualidad que prácticamente todas las historiografías del mundo occidental -y posiblemente más allá- comiencen, después de 1968, a ocuparse de todo el conjunto de nuevos temas cuyo denominador común es el de ser temas de historia cultural, los que además van a provocar para su estudio también una multiplicación importante de nuevos enfoques, conceptos y aproximaciones. Pues es claro que es siempre el espíritu del 68 y de sus múltiples efectos el que se hace presente tanto en los estudios de la psicohistory inglesa como en los múltiples y heterogéneos modelos de la confesamente ambigua histoire des mentalités francesa, pero también e igualmente en la new intellectual history norteamericana, en la rama de historia cultural de la microstoria italiana, en la historia británica de la popular culture, o en la Altagsgeschichte alemana, entre tantas otras expresiones. ${ }^{12}$

Creando entonces un movimiento internacional que aflora simultáneamente en los años setenta en múltiples puntos del planeta, es que los historiadores post-68, se han puesto a investigar los nuevos y hasta entonces casi inexplorados temas de la historia de la familia y de la sexualidad, de la historia de las actitudes ante la muerte o ante la locura, del desciframiento del rito y del mito del Aquelarre o de la evolución de las costumbres, de la

12 Nos referimos a todo ese conjunto de obras y de aproximaciones que, desde 1968, han intentado problematizar desde muy diversos ángulos el renglón de la cultura. A título solo de muestra, véanse por ejemplo las reflexiones metodológicas que este movimiento ha suscitado en los textos de Le Goff (1980), Ginzburg (1994 y 2014), Gay (1985), Thompson (1978), Darnton (1990), o Lüdtke (1994). 
historia de las mujeres y de la imagen del niño en el Antiguo Régimen, de la cultura popular en la edad moderna y de la cosmovisión de los oprimidos en el siglo XVI, de las tradiciones y el folklore de una clase obrera en formación o de los imaginarios populares en el Antiguo Régimen francés, entre tantos y tantos temas de historia cultural que desde entonces han sido abordados.

Al mismo tiempo, y junto a esta apertura de temas antes poco tratados o simplemente ignorados por la historiografía, ${ }^{13}$ va a desarrollarse paralelamente un intenso y también plurifacético trabajo de reflexión metodológica, que intenta, por una parte, construir las categorías más adecuadas para el estudio y explicación de esas realidades culturales, y, por otra, crear ambiciosos modelos globales para la interpretación de estos mismos fenómenos del orden cultural. Y entonces, criticando lo mismo las insuficiencias y ambigüedades del concepto francés de las "mentalidades" que el rígido esquema de difuminación siempre en un solo sentido desde la cultura de la elite hacia la cultura popular, que adentrándose en el debate de las complejas relaciones entre folklore, tradición y cultura, o en las posibilidades del método isomórfico en la reconstrucción de afinidades históricas culturales, los practicantes de Clío han pasado, después de 1968, desde la anacrónica y limitada historia de las ideas hacia una nueva y más elaborada historia social de las distintas prácticas culturales, o hacia las más recientes versiones de esa nueva historia de la cultura. ${ }^{14}$

Simultáneamente, y como un complemento casi espontáneo de esta renovación de la agenda de temas de los historiadores, que ahora incorpora de pleno derecho a estos temas culturales, y gracias al desarrollo ya mencionado de esos nuevos enfoques y modelos para su tratamiento y abordaje, se ha dado también una profunda renovación en el modo de acercarse a los viejos temas historiográficos, los que desde estas perspectivas post-68 van a ser aprehendidos de una manera radicalmente distinta. Por ejemplo, las viejas y tradicionales historias del movimiento obrero, que concentraban siempre su atención en la historia de los líderes y de las élites obreras, y en el destino político de los movimientos estudiados, y que desde hace medio siglo van a abordar más bien la transformaciones de las costumbres y de la vida cotidiana de las masas obreras a raíz de esos mismos movimientos, preguntándose además sobre los efectos de dichos movimientos sobre la conciencia obrera y sobre sus formas de organización y de trabajo más cotidianas y elementales. O también, en el caso del estudio de los procesos económicos y sociales, como por ejemplo el de la formación de un mercado interno o el del tránsito

13 Lo que resalta el valor del trabajo pionero de Norbert Elías, en sus obras El proceso de la civilización (1987) o La sociedad cortesana (1982). Sobre este punto, cfr. Aguirre (2010a).

14 Sobre esta historia cultural mencionada véanse las obras de Chartier (1992 y 1998), Boureau (1989) y Ginzburg (1991a, 2000, 2010 y 2016). 
del mundo feudal al mundo moderno capitalista, procesos que van a dejar de estudiarse como si fuesen solo grandes movimientos impersonales y anónimos, para ser ahora investigados en sus efectos y consecuencias reales sobre las poblaciones campesinas y sobre los estratos urbanos, vistos además en sus singularidades concretas y en el complejo entramado de cambios de valores, actitudes culturales, percepciones intelectuales y cosmovisiones de todo orden que ellos entrañan. ${ }^{15}$

\section{La historia en la nueva constelación de las ciencias sociales}

También después de 1968 se ha colapsado el "sistema de saberes" que se fue construyendo durante la segunda mitad del siglo XIX, y que al ir multiplicando constantemente y afianzando progresivamente a nuevas y nuevas "disciplinas" o ciencias sociales, terminó por establecer como estrategia de aprehensión epistemológica de "lo social" a ese cúmulo de ámbitos especializados entre sí y supuestamente autónomos que fueron las diversas ciencias sociales del siglo XX. Distintas ciencias sociales que recortaban a esa compleja unidad de lo social, postulando que dicho recorte correspondía efectivamente a la propia realidad, la que entonces nos daba, según esta visión, un objeto económico junto a un campo psicológico, una esfera puramente política y una dimensión exclusivamente social, un ámbito solo geográfico y un espacio reservado para la antropología, y en consecuencia el fundamento necesario para que cada una de estas "ciencias" o "disciplinas" elaborase y reivindicase para sí su propio objeto de estudio, sus técnicas específicas, sus conceptos particulares y sus métodos completamente singulares. ${ }^{16}$

Sin embargo, y a pesar de haberse afirmado como el "episteme" dominante dentro del conocimiento sobre lo social durante el último tercio del siglo XIX y los dos primeros tercios del siglo XX, este sistema de saberes parcelado, autonomizado y basado en la especialización mostró rápidamente sus límites epistemológicos, siendo criticado y cuestionado prácticamente por todas las corrientes innovadoras y por todos los pensadores críticos de esta centuria que corre entre 1870 y 1968, aproximadamente. ${ }^{17}$ Una crítica reiterada a las limitaciones de este modo de aproximación hacia lo social, que

15 En esta línea, son interesantes todos los trabajos producidos por los distintos representantes de la microstoria italiana. A título solo de ejemplo cfr. Levi (1990), Gribaudi (1987), Cerutti (1990), Ginzburg (1984 y 1991) y Ginzburg y Prosperi (1975).

16 Cfr. al respecto Wallerstein et. alt. (1996) y también Aguirre (2004).

17 Cfr. por citar solo un ejemplo, el caso de la corriente de los Annales y su defensa permanente del paradigma de la historia global. Al respecto véase Aguirre (1996, 1999, 2000, 2006, 2017a y 2017b). 
estará también en el centro de las impugnaciones de 1968, ejerciendo sus efectos sobre todo el conjunto de esas disciplinas sociales y también sobre la propia historiografía. ${ }^{18}$

Pues no es simplemente por azar que después de 1968 van a prosperar y a ponerse de moda en el mundo entero los proyectos, institutos, perspectivas, centros y enfoques, multi/pluri/trans/intersdisciplinarios, los que en su conjunto solo expresan, aún de modo incipiente y limitado, el verdadero proceso desencadenado desde hace cinco décadas, proceso que en el fondo marcha hacia la construcción de una nueva configuración del sistema de saberes, hacia un nuevo "episteme" dominante para el estudio y aprehensión de la realidad, tanto social como en general. ${ }^{19}$

Nueva situación del saber sobre lo social en proceso de gestación y maduración que, en términos inmediatos y para el específico ámbito de la historiografía, ha redefinido la relación de alianzas y de vínculos de esta última con todas las restantes ciencias sociales. Así, en los últimos diez lustros, hemos pasado claramente de una situación de vínculos acotados y generalmente biunívocos que la historia iba estableciendo en sus diferentes momentos con la economía, la sociología, la geografía o la demografía, a una nueva situación en la que la historia se abre permanentemente y sin excepción a todas las distantes ciencias sociales, con las que se mezcla y fecunda recíprocamente, en un diálogo múltiple que legitima y concretiza el viejo paradigma de la historia global. Paradigma defendido por Marx y por los marxistas, igual que por los Annales y por toda corriente historiográfica innovadora, que en el fondo apunta, en su sentido último y más radical, hacia la supresión de esas barreras disciplinarias y hacia la constitución del nuevo episteme o sistema de los saberes ya aludido.

Nuevo concierto de muchas voces, de la historia con todas las disciplinas sociales, que se ejemplifica paradigmáticamente con la apertura hacia la antropología, respecto de la cual la historia va a recuperar, después de 1968, prácticamente el conjunto global de sus aportaciones. Pues lo mismo los temas clásicos de la antropología, ocupada tradicionalmente en el estudio de las costumbres, de la vida cotidiana, de las relaciones de parentesco o de los mitos, que sus técnicas más características, como la encuesta y la observación participante, van a ser retomadas por la historia, la que en los últimos cincuenta años se ha convertido lo mismo en historia de la vida cotidiana que en historia de la familia y de la sexualidad, pero también en

18 Sobre esta crisis del sistema de los saberes, y sobre algunas de sus implicaciones hacia la historia, cfr. Foucault (1985 y 1986).

19 Sobre este problema cfr. los trabajos incluidos en el número especial de Review, vol. XV, núm. 1, Binghamton, 1992. 
historia de la civilización material y de los arquetipos culturales, anexando a sus territorios de investigación a todas esas dimensiones y problemas antes reservadas al examen de los antropólogos. Lo que igualmente se repite en el caso de las técnicas antropológicas antes mencionadas, las que desde el lado de la historia van a reproducirse, como ya hemos referido, bajo las formas de la historia oral y de la historia construida con las mismas clases populares, desde la inmersión absoluta en sus luchas y en su práctica cotidiana y regular.

Pero también la historia va a impregnarse del legado de la antropología, al intentar copiar sus métodos principales, interesándose en el análisis directo y minucioso de las experiencias vividas por los distintos personajes históricos y en un acercamiento más estrecho a la dimensión concreta de sus objetos analizados, lo mismo que en la aprehensión de las perspectivas y de las "miradas" específicas, que hacen posible captar esos problemas del folklore, de la tradición, de las creencias y de las cosmovisiones a las que está habituada esa misma antropología. Finalmente, readaptando dentro de la historia conceptos y modelos desarrollados dentro de la antropología, como el de la dialéctica macro/micro, el del análisis de las redes sociales, el del estudio de los fenómenos 'en situación', o el de la reconstrucción global de una "descripción densa", los practicantes de Clío le han dado vida a esa historia antropológica o antropología histórica que tanto éxito y desarrollo han tenido en las últimas décadas recién vividas. ${ }^{20}$

\section{De la historia general a la historia viva}

Al apoyarse de manera central en un nuevo sujeto social contestatario, en el sector de los estudiantes, hasta entonces poco protagónico, y que desde la fecha de 1968 se ha manifestado como un sujeto particularmente activo dentro de los movimientos antisistémicos, el movimiento de hace cinco décadas puso en cuestión la validez absoluta de los grandes modelos generales que habían sido elaborados muchos años atrás, y cuya vigencia total había sido considerada como legitima e incuestionable durante un largo periodo de décadas.

Pero al colocar en todo el mundo, en el centro de los movimientos del 68, a ese nuevo sujeto estudiantil, 1968 ponía a prueba los viejos esquemas del cambio social, desencadenando la crisis universal de las viejas izquierdas, y abriendo el desarrollo múltiple y plural de todos los movimientos sociales y

20 Dos claros ejemplos de este acercamiento intenso de la historia con la antropología serían tanto el de la historia marxista de E. P. Thompson, como el de la mayoría de los autores de la importante corriente de la microhistoria italiana. Sobre el punto, cfr. Thompson (1994) y Revel (1996). 
de todas las nuevas izquierdas que llenan el paisaje del mundo de la oposición y de la resistencia anticapitalista del último medio siglo vivido.

De este modo, 1968 es también una ruptura con esos modelos generales, abstractos, rígidos y casi siempre vacíos que eran defendidos por esa vieja izquierda y que proclamaban que solo la clase obrera era revolucionaria, que solo las demandas económicas y políticas eran legítimas, y que la historia marchaba de manera forzosa y casi automática hacia el socialismo. Pero los distintos movimientos de fines de los sesentas lo que justamente demostraban era que no hay automatismo alguno en la historia y que esta última la hacen los hombres, lo que implica que con la complejización del capitalismo también se hacen más complejos y diversos los frentes del combate anticapitalista, y que en función de la expansión y difusión tanto extensivas como intensivas de la explotación y de la opresión capitalistas, deben también multiplicarse y diversificarse los movimientos y los actores de oposición al mismo.

Entonces, con la crisis de la vieja izquierda vino la crisis de esos modelos generales incapaces de aprehender la realidad, ${ }^{21}$ a la vez que una exigencia explícita de reintroducir en el análisis el elemento vivo de la historia, la dimensión realmente vivida por los actores y, más en general, la reivindicación de la necesidad de rescatar, en las ciencias sociales, todo el conjunto de esos elementos histórico-concretos que poco a poco habían sido progresivamente evacuados por los analistas sociales, y que habían terminado por convertir a dichos modelos en simples ensamblajes de estructuras abstractas, rígidas y completamente vacías de contenido.

Lo que en el campo de la historiografía fue asumido de dos maneras diametralmente opuestas. De un lado, y siguiendo la línea más cómoda pero también más estéril, a través de la posición posmoderna, la que frente a esa crisis real de los modelos generales, simplemente optó por negar todo modelo general, afirmando que había llegado la época del fin de los "metarrelatos" y de las "grandes construcciones", y desembocando en posturas relativistas y logocéntricas que de plano niegan el carácter científico de la historia, y que intentan reducirla a su sola condición discursiva, desembocando entonces en un verdadero callejón sin salida para esta misma historiografía. ${ }^{22}$

Del otro lado y en una visión mucho más compleja y difícil, pero también más fructífera, esta crisis de los modelos generales y la concomitante demanda de restituir sus derechos a las dimensiones histórico-concretas,

21 Una crítica pionera y anticipatoria de este trazo post-68 de las ciencias sociales, es la critica a los modelos vacíos y rígidos defendidos por la variante correspondiente al marxismo vulgar, manualesco y simplificado que ha sido cultivado por la mayoría de los partidos comunistas en todo el mundo, y que está contenida en la obra de Sartre (1970).

22 Es el caso de obras como las de Veyne (1978) y de De Certeau (1985). 
dio nacimiento a todos esos múltiples esfuerzos que, después de 1968, pasaron de la historia de las estructuras a la historia de los actores, de la historia de las realidades económicas y sociales a la historia de la subjetividad y de las percepciones culturales, de la historia del poder a la historia de las resistencias y de la insubordinación, de las historias generales a las historias locales y regionales, de los procesos macrohistóricos a los universos microhistóricos, de la historia de las leyes y las normas a la historia de los casos individuales atípicos y de las desviaciones, y de la historia de los grupos establecidos y centrales a la historia de las minorías, de los marginales y de los pequeños grupos.

Un movimiento plurifacético y complejo de muchas y muy distintas aristas, cuyo sentido general no es para nada el de renunciar a los modelos generales y a la macrohistoria, sino más bien el de volver a nivelar la balanza del análisis histórico, reintroduciendo junto a estas coordenadas estructurales y más universales de la historia también a todo ese conjunto de dimensiones histórico-concretas, y de niveles y realidades complementarias de dichas coordenadas. Así, restituyendo las distintas dialécticas de lo general/particular, macro/micro, estructuras/actores, economía/cultura, poder/resistencias, global/regional-local, normas/casos y centros/márgenes, los historiadores post-68 han recomplejizado una vez más el oficio de historiador, reintroduciendo de nueva cuenta el rol activo y creador de los sujetos históricos en la construcción de su propia historia. Con lo cual se hacen eco y dan otra vez sentido a esa consigna del 68, aparentemente paradójica, pero completamente realizable que recomendaba sabiamente: "seamos realistas, pidamos lo imposible".

\section{8: ¿la apertura de una nueva situación de bifurcación histórica?}

Junto a estos cambios mencionados y de una manera más general, 1968 ha cambiado también el modo mismo de funcionar y de interconectarse entre sí del conjunto de las historiografías nacionales, incorporadas más globalmente dentro del cosmos de lo que podríamos llamar la "historiografía occidental". Pues si analizamos desde una perspectiva de larga duración el entero periplo de la curva de la historiografía contemporánea, de esa historiografía que arranca claramente con Marx en la segunda mitad del siglo XIX y que se despliega hasta el día de hoy, nos llamará de inmediato la atención el cambio producido una vez más por la ruptura profunda de $1968 .^{23}$

23 Cfr. sobre este punto, Aguirre (2011). 
Porque antes de 1968 los estudios históricos han funcionado claramente bajo el esquema de constituir siempre un centro hegemónico historiográfico, un espacio nacional o regional en el que nueve de cada diez veces se generan y se producen las más importantes innovaciones historiográficas en curso, escenificándose los grandes debates históricos de la época y escribiéndose las que más adelante serán las obras "clásicas" de la historiografía en ese mismo periodo. Y así, es claro que entre 1870 y 1930 ha sido la historiografía germanoparlante, alemana y austríaca, la que ha jugado ese rol de líder dentro del paisaje historiográfico del mundo occidental, construyendo el "modelo dominante a imitar" por parte de las restantes historiografías de Europa y del mundo, e instituyendo el entonces célebre "viaje a Alemania" como una actividad obligada en la formación de todo historiador que pretendiera estar a la altura real de las exigencias del oficio en esos años de fines del siglo XIX y principios del siglo XX.

Un claro modelo de funcionamiento de un centro hegemónico en la historiografía, rodeado de múltiples espacios historiográficos que giran en torno a él y que legitiman y reproducen dicha hegemonía al reconstruir a su manera las propuestas metodológicas, los modelos de investigación y los nuevos campos problemáticos que ese centro genera. Un modelo que entre 1930 y 1968 ha ubicado dicha dominación dentro del hexágono francés, dándole a Francia el cuasimonopolio en el descubrimiento e invención de los nuevos paradigmas, conceptos, problemas y desarrollos de la historiografía de esas cuatro décadas intermedias del siglo XX cronológico. Modo asimétrico de funcionar del conjunto de las historiografías nacionales del mundo occidental, que se rompe igualmente a consecuencia de los profundos cambios aportados por la revolución cultural de 1968.

Y si ahora, siguiendo este recorrido de la curva entera de la historiografía contemporánea, nos preguntamos ¿quién ha sucedido a Francia, después de 1968, en ese puesto de comando y de dominación de los estudios históricos occidentales?, nos daremos cuenta de que no existe dicho sucesor, pues también ha cambiado en estos últimos cincuenta años el modo de interconectarse de las historiografías nacionales. Y entonces ahora no existe más un centro hegemónico dentro del panorama occidental y mundial, pues la innovación historiográfica se genera y se procesa hoy en día, y desde hace ya diez lustros, a todo lo largo y ancho del tejido de esa misma historiografía planetaria. Con lo cual, en las cinco décadas posteriores a 1968, van a ser tan importantes los terceros y los cuartos Annales franceses (hoy en franca y absoluta decadencia), - las varias ramas de la microhistoria italiana, como los representantes de la nueva historia radical norteamericana o la nueva historia social alemana, pasando entre muchas otras, por la reciente historia institucional portuguesa, la renovada historia regional latinoamericana, la antropología histórica rusa o las varias corrientes de la historia marxista británica. 
Múltiples expresiones de la renovación historiográfica post-68, ahora presente en todas partes, que solo atestiguan acerca de la constitución de una novedosa e inédita situación, caracterizada hoy por el policentrismo en la innovación historiográfica y por la pluralidad de alternativas de desarrollo de la investigación histórica, trazos ambos que definen centralmente a la nueva modalidad de funcionamiento y al nuevo modo de interconexión entre las historiografías locales y nacionales del mundo entero.

Situación policéntrica y plural que, por lo demás, no parece ser exclusiva de la historiografía, y ni siquiera de las ciencias sociales o incluso de la cultura en general de los últimos cincuenta años, sino que parecería extenderse mucho más allá, para presentarse como uno de los trazos tal vez generales de la situación global del capitalismo mundial posterior a 1968.

Pues si abrimos nuevamente nuestra perspectiva de análisis y desde la historiografía nos remontamos hacia la cultura en general, y más allá a la sociedad en su conjunto, observaremos que esa crisis del modelo construido en torno a una clara centralidad de uno de sus elementos es una crisis mucho más extendida y universal, que abarca lo mismo a los movimientos sociales que a sus demandas más tradicionales y consagradas, pero también al modo de articulación de las relaciones económicas internacionales o a las formas de reproducción sociales en su conjunto. Y así, después de los cambios fundamentales de 1968-1972/73, Estados Unidos ha dejado de ser el centro hegemónico de la economía y de la geopolítica mundiales, perdiendo su antigua centralidad para dar paso a una nueva situación más bien policéntrica, en la que ahora se enfrentan y combaten por el dominio los distintos bloques económicos transnacionales en proceso de construcción. O también el caso de la clase obrera, que ha dejado de ser el único agente revolucionario y centro indisputado de los movimientos sociales antisistémicos, para ser sustituido por una nueva y compleja constelación de nuevos sujetos y movimientos sociales anticapitalistas, tan policéntrica y plural como la multiplicación de los frentes y los espacios de la explotación y de la opresión capitalistas, y con ellos, de la resistencia y la rebeldía de las clases y los sectores subalternos y de esos mismos movimientos antisistémicos actuales.

Un proceso de tránsito desde una situación concéntrica hasta una nueva situación de pluralidad policéntrica, que se registra también en el nivel de las demandas de esos nuevos movimientos sociales, demandas que han dejado de ser centralmente económicas o políticas, para diversificarse y pluralizarse en las distintas demandas feministas, pacifistas, ecologistas, urbanas, antirracistas, étnicas, comunitarias o de las muchas minorías reprimidas que afloran a la palestra de las luchas sociales después de 1968. O también en el claro movimiento del conjunto de la esfera cultural, en donde la antigua situación de dominación de ciertos patrones culturales, o de ciertas culturas 
dominantes, por ejemplo, en el ámbito artístico, ha terminado, para dar paso al florecimiento de expresiones culturales diversas, que coexisten y dialogan por todo el mundo sin claras jerarquías establecidas y sin ningún tipo de exclusión. Y entonces, Europa deja de ser el centro irradiador de la cultura dominante en todo el mundo occidental, en el mismo momento en que la música, la escultura, la pintura y las artes de todas las regiones del mundo se universalizan y difunden por doquier, afirmándose como otras tantas cosmovisiones culturales, alternativas y posibles, dentro de la nueva situación de policentrismo cultural y social.

Movimiento donde los centros decaen y donde el rol mismo de la centralidad como mecanismo global de funcionamiento social es deslegitimado en sus propios fundamentos, que está expresando en el fondo la apertura de una nueva y radicalmente distinta situación del capitalismo mundial, el que luego de 1968-73 habría comenzado a entrar en una clara situación de bifurcación histórica, es decir, en la clara etapa de su crisis terminal definitiva. ${ }^{24}$ Situación de bifurcación en la que dejarían de funcionar los mecanismos de estabilización y reproducción del sistema capitalista mundial en su conjunto, anunciando tanto su inevitable fin como la imperiosa necesidad de su mutación y transformación profundas.

Con lo cual, y siguiendo esta hipótesis de Immanuel Wallerstein, podríamos preguntarnos si 1968 no tendría entonces, además de su profundo carácter como revolución cultural de alcance planetario y de consecuencias civilizatorias, todavía una nueva y adicional significación suplementaria: es decir, la de haber inaugurado con su propia irrupción esa fase claramente terminal de la vida del capitalismo moderno iniciada hace más o menos cinco siglos.

Pero como bien nos lo ha recordado la generación "soixante-huitard" en el mundo entero, la historia no es un proceso automático y de un solo sentido ineluctable, sino que es un proceso que hacemos los propios hombres, los que con nuestra acción colectiva y nuestras reflexiones ayudamos a decidir sus posibles destinos, de acuerdo a las condiciones de posibilidad de cada momento histórico específico.

Entonces, depende justamente de esas acciones colectivas y de ese trabajo de comprensión intelectual el que 1968 pueda ser recordado, tal vez en el año de 2068, cien años después de su saludable y benéfica irrupción, como ese momento de umbral que inauguró con su desarrollo, la etapa final del sistema histórico capitalista mundial, y la clara transición hacia un mundo no capitalista, en el que la explotación económica, la opresión política y toda for-

24 Es esta la hipótesis planteada por Wallerstein (ver nota 3). Además, cfr. Wallerstein (1996). 
ma de discriminación social pasaron a ser solo malos recuerdos de un pasado finalmente superado. $Y$ tal vez ni siquiera haya que esperar hasta ese año de 2068, para que esta última y más profunda significación de 1968 pueda ser reconocida por todos. En cualquier caso, 1968 sigue ahí, cincuenta años después de su radical irrupción y con todas sus lecciones y efectos principales, para continuar incitándonos, día a día, a que trabajemos activamente para honrar su legado, enterrando al nefasto capitalismo actual y ayudando a alumbrar a la nueva sociedad libre, justa e igualitaria que todos anhelamos.

\section{Referencias bibliográficas}

\section{Fuentes primarias}

\section{a) Publicaciones periódicas}

Dossiers et Documents de Le Monde, abril de 1998, № 264.

Review, vol. XV, № 1, 1992.

History Workshop.

\section{Fuentes secundarias}

a) Artículos y capítulos de libros

Aguirre, C. (1993). "1968: la gran ruptura", en La Jornada Semanal, № 225, 3 de octubre, pp. 18-22.

Aguirre, C. (2008). "La revolución mundial de 1968, cuatro décadas después", en Contrahistorias. La otra mirada de Clío, № 11, pp. 51-58.

Arrighi, G.; Hopkins, T. y Wallerstein, I. (1992). "1989, The Continuation of 1968", en Review (Fernand Braudel Center), Vol. XV, N 2, pp. 221-242.

Boureau, A. (1989). "Propositions pour une histoire restreinte des mentalités", en Annales. Économies, Sociétés, Civilisation., vol. 44, № 6, Paris, nov-dic, pp. 1491-1504.

Braudel, F. (1993). "Renacimiento, Reforma, 1968: revoluciones culturales de larga duración" en La Jornada Semanal, № 226, 10 de octubre, pp. 27-32.

Dosse, F. (1989). "Mai 68: les effets de l'Histoire sur l'histoire", en Cahiers de I'IHTP, No 11, abril, pp. 96-101.

Dosse, F. (1998). "Les mots pour le dire", en Page des libraires, № 50, febreromarzo. 
Wallerstein, I. (1989). "1968: revolución en el sistema-mundo. Tesis e interrogantes", en Estudios Sociológicos, № 20, pp. 229-250.

Zancarini-Fournel, M. (1998). "Changer la vie. Une histoire sociale des années 68", en Page des libraires, N 50, febrero-marzo.

\section{b) Libros}

Aguirre, C. (1996). Los Annales y la historiografía francesa. México: Quinto Sol.

Aguirre, C. (1999). Itinerarios de la historiografía del siglo XX. La Habana: Centro de Investigaciones Juan Marinello.

Aguirre, C. (2000). Ensayos Braudelianos. Rosario: Manuel Suárez Editor.

Aguirre, C. (2004). Immanuel Wallerstein: Crítica del sistema-mundo capitalista. Santiago de Chile: LOM Ediciones.

Aguirre, C. (2006). La Escuela de los Annales. Ayer, hoy, mañana. Rosario: Prohistoria Ediciones.

Aguirre, C. (2010a). De Carlos Marx a Immanuel Wallerstein. Nueve ensayos de historiografía contemporánea. Santiago de Chile: Universidad Católica Silva Henríquez.

Aguirre, C. (2010b). Para comprender el mundo actual. México: Instituto Politécnico Nacional.

Aguirre, C. (2011). La historiografía en el siglo XX. La Habana: Instituto Cubano de Arte e Industria Cinematográficos.

Aguirre, C. (2017a). Antimanual del mal historiador. Santiago: Editorial Quimantú.

Aguirre, C. (2017b). Fernand Braudel y las ciencias humanas. Bogotá: Ediciones Desde Abajo.

Benjamin, W. (1983a). Essais I. París: Editorial Denoël/Gonthier.

Benjamin, W. (1983b). Essais II. París: Editorial Denoël/Gonthier.

Braudel, F. (1997). Les ecrits de Fernand Braudel. Les ambitions de l'histoire. París: Editions de Fallois.

Cerutti, S. (1990). La ville et les metiers. París: Editions de l'Ecole des Hautes Etudes en Sciences Sociales.

Chartier, R. (1992). El mundo como representación. Barcelona: Gedisa.

Chartier, R. (1998). Au bord de la falaise. París : Albin Michel. 
Darnton, R. (1990). The kiss of Lamourette. Reflections in cultural history. Nueva York: W. W. Norton \& Company.

De Certeau, M. (1985). La escritura de la historia. México: Universidad Iberoamericana.

Elías, N. (1982). La sociedad cortesana. México: Fondo de Cultura Económica. Elías, N. (1987). El proceso de la civilización. México: Fondo de Cultura Económica. Faure, C. (1998). Mai 68. Jour et nuit. París: Gallimard.

Foucault, M. (1985). La arqueología del saber. México: Editorial Siglo XXI. Foucault, M. (1986). Las palabras y las cosas. México: Editorial Siglo XXI. Foucault, M. (1993). Vigilar y castigar. México: Editorial Siglo XXI. Gay, P. (1985). Freud for historians. Oxford: Oxford University Press. Ginzburg, C. (1984). Pesquisa sobre Piero. Barcelona: Muchnick Editores. Ginzburg, C. (1991a). Historia nocturna. Barcelona: Muchnick Editores. Ginzburg, C. (1991b). El queso y los gusanos. Barcelona: Muchnick Editores. Ginzburg, C. (1994). Mitos, emblemas, indicios. Barcelona: Gedisa. Ginzburg, C. (2000). Ojazos de madera. Barcelona: Península. Ginzburg, C. (2010). El hilo y las huellas. Buenos Aires: Fondo de Cultura Económica.

Ginzburg, C. (2014). Miedo, Reverencia, Terror. Cinco ensayos de Iconografía Política. México: Contrahistorias.

Ginzburg, C. (2016). Ninguna isla es una isla. Rosario: CEHISO, Prohistoria. Ginzburg C. y Prosperi, A. (1975). Giochi di Pazienza. Turín: Einaudi.

Gribaudi, M. (1987). Itineraires ouvriers. Espaces et groupes sociaux à Turin au début du XXeme siècle. París: Editions de l'Ecole des Hautes Etudes en Sciences Sociales.

Hobsbawm, E. (1996). Historia del siglo XX. Barcelona: Crítica.

Hopkins T. y Wallerstein, I. (coords.). (1996). The Age of transition. Trajectory of the world-system 1945-2025. Londres: Zed Books.

Joutard, P. (1983). Ces voix qui nous viennent du passé, Paris: Hachette.

Le Goff, J. (1980). Hacer la historia, vol. 3. Barcelona: Editorial Laia.

Le Goff, J. (1998). Mai 68. L'heritage impossible. París: La Decouverte. 
Levi, G. (1990). La herencia inmaterial. Barcelona: Editorial Nerea.

Lüdtke, A. (1994). Histoire du quotidien. París: Éditions de la Maison des Sciences de l'Homme.

Revel, J. (1996). Jeux d'echelles. La micro-analyse à l'expérience. París: Gallimard/ Le Seuil.

Samuel, R. (editor). (1975). Village life and Labour. Londres: Routledge and Kegan Paul.

Samuel, R. (editor). (1984). Historia popular y teoría socialista. Barcelona: Crítica/ Grijalbo.

Sartre, J.-P. (1970). Crítica de la razón dialéctica. Buenos Aires: Editorial Losada.

Thompson, E. P. (1978). The poverty of theory. Londres: Merlin Press.

Thompson, E. P. (1994). Historia social y antropología. México: Instituto Mora.

Thompson, P. (1975). The Edwardians: the remaking of British society. London: Weidenfeld and Nicolson.

Veyne, P. (1978). Comment on écrit l'histoire. Paris: Editorial du Seuil.

Wallerstein, I. (1996). Después del liberalismo. México: Editorial Siglo XXI.

Wallerstein, I. et al. (1996). Abrir las ciencias sociales. México: Editorial Siglo XXI. 